\title{
Effect of Land Use on Organic Carbon Storage Potential of Soils with Contrasting Native Organic Matter Content
}

\author{
Sabina Yeasmin (D, ${ }^{1,2}$ Eshara Jahan, ${ }^{1,2}$ Md. Ashik Molla,,2 A. K. M. Mominul Islam ${ }^{10},{ }^{1,2}$ \\ Md. Parvez Anwar $\mathbb{B}^{1,},{ }^{1,2}$ Md. Harun Or Rashid, ${ }^{1}$ and Sirinapa Chungopast ${ }^{3}$ \\ ${ }^{1}$ Department of Agronomy, Bangladesh Agricultural University, Mymensingh 2202, Bangladesh \\ ${ }^{2}$ Agro Innovation Laboratory, Department of Agronomy, Bangladesh Agricultural University, Mymensingh 2202, Bangladesh \\ ${ }^{3}$ Department of Soil Science, Faculty of Agriculture, Kasetsart University Kamphaeng-Saen Campus, \\ Nakorn Pathom 73140, Thailand \\ Correspondence should be addressed to Sabina Yeasmin; sabinayeasmin@bau.edu.bd
}

Received 26 December 2019; Accepted 10 March 2020; Published 31 March 2020

Academic Editor: David Clay

Copyright (c) 2020 Sabina Yeasmin et al. This is an open access article distributed under the Creative Commons Attribution License, which permits unrestricted use, distribution, and reproduction in any medium, provided the original work is properly cited.

\begin{abstract}
This study aimed to determine the impact of land use on organic carbon (OC) pools of soils with contrasting native organic matter $(\mathrm{OM})$ content. Surface $(0-15 \mathrm{~cm})$ soils of four land uses (cropland, orchard, grassland, and fallow) were collected from four agroecological zones (AEZs) of Bangladesh with different OM content (AEZ-7: very low, -3: low, -9: medium, and -5: high). Bulk soils were physically fractionated into particulate and mineral associated OM (POM and MOM: $>53$ and $<53 \mu \mathrm{m}$, respectively). Both bulk and fractionated soils were analyzed for OC and nitrogen $(\mathrm{N})$. Among the land uses, undisturbed soils (grassland and fallow land) had significantly higher total OC (0.44-1.79\%) than disturbed soils (orchard and cropland) (0.39-1.67\%) in all AEZs. The distribution of OC and N in POM and MOM fractions was significantly different among land uses and also varied with native OM content. In all AEZs, cropland soils showed the lowest POM-C content (0.40-1.41\%), whereas the orchard soils showed the highest values $(0.71-1.91 \%)$. The MOM-C was highest (0.81-1.91\%) in fallow land and lowest (0.53-1.51\%) in orchard, and cropland had a moderate amount $(0.70-1.61 \%)$. In croplands, distribution of a considerable amount of OC in the MOM pool was noticeable. These findings reveal that total OC in soils can be decreased with cultivation but does not inevitably indicate the loss of OC storage in the stable pool. Carbon storage potential of soils with both high- and low-native OM contents can be increased via proper land use and managements.
\end{abstract}

\section{Introduction}

Soil carbon (C) sequestration, i.e., the process of capturing and storing of atmospheric $\mathrm{CO}_{2}$ in soil for a long term [1] is one of the potential options for slowing the rise of $\mathrm{CO}_{2}$ concentrations in the atmosphere. Soil is the largest reservoir of C, storing approximately $53 \%$ of the terrestrial C [2]. However, whether the soils will act as a sink or as a source of $\mathrm{CO}_{2}$ is highly dependent on several factors, including soil properties and land use [3-5].

Land use and vegetation type vastly influence soil disturbance and $\mathrm{C}$ dynamics. Land use and management that exerts the least soil disturbance contributes to increase soil
OC accumulation, while intensive disturbance results in lower soil OC and consequent soil degradation [6]. Land use change from native ecosystem (grassland/forest) to cultivated ecosystem causes loss of soil C up to $50 \%$ [6-9]. On the other hand, vegetation development on abandoned agricultural land enhances the $\mathrm{C}$ sequestration [2]. Cultivated systems may reduce $\mathrm{C}$ contents due to reduced yearly $\mathrm{C}$ input and increased mineralization due to surface disturbance [10]. However, the extent of the land use effect on soil $\mathrm{C}$ is not always equal in all soils. Soils could vary in mineral composition, microbial population, native organic matter (OM) content, etc. Among all properties, native soil OM content is an important factor for soil OC accumulation. 
Native soil OM levels reflect the balance of C inputs and C losses under natural conditions. Soils can sequester additional $\mathrm{C}$ through increasing $\mathrm{C}$ input and/or decreasing $\mathrm{C}$ harvest by practicing improved land use and crop management. Levels of $\mathrm{C}$ in long-term grassland, pastoral land, and even agricultural land can exceed their native $\mathrm{C}$ with proper land use and management system [11]. Several longterm field experiments reported a proportional relationship between $\mathrm{C}$ inputs and soil native $\mathrm{C}$ content $[12,13]$, some experiments in high $\mathrm{C}$ soils showed little or no increase in soil $\mathrm{C}$ content with 2 to 3 -fold increases in C inputs $[13,14]$. Hence, native soil $\mathrm{C}$ levels may not be an appropriate measure of the ultimate $\mathrm{C}$ sink capacity of soils. Individual soil has a limit for maximal C storage, it is called C saturation limit which is related to the maximum ability of soil aggregates and clay minerals for soil OC protection, as for example, organo-mineral interactions [15-17].

Generally, plant biomass is the primary source of soil OC. When biomass decomposes, it is incorporated into soil OC. Some parts of OC degrade easily, known as labile OC, whereas another part decomposes slowly takes hundreds to thousand years, known as stable OC [18]. The stable OC is protected from decomposition mainly through different stabilization mechanisms and contribute to $\mathrm{C}$ sequestration. Labile OC is presumably more sensitive to land use change compare to the stable OC [19]. Therefore, considering the total soil OC as a homogenous single pool overlooks the difference in relative abundances and potentiality of the distinct sequestered OC pool in response to land use system $[20,21]$.

Numerous works has been done on studying the effect of land use on soil OC. But most of them have focused on either the changes in total soil OC [22-24] or did not take into account soil variability or even generalized land use and management practices for soils with variable native OM. Therefore, this study aimed to evaluate the effect of existing land use on soil C storage potential in soils with contrasting native $\mathrm{OM}$ content. The objectives of this present study were: (a) to quantify total OC, easily degradable (labile) and relatively sequestered $\mathrm{C}$ (stable), in the selected soils, (b) to evaluate the land use impact on total and two different OC pools (labile and stable) in the selected soils, and (c) to examine the $\mathrm{C}$ storage potential in soils with different native OM contents.

\section{Materials and Methods}

2.1. Sampling Sites. Soil samples were collected from farmers field in agroecological zones (AEZ)-7 (active BrahmaputraJamuna floodplain), 3 (Tista Meander floodplain), 9 (Old Brahmaputra floodplain), and 5 (lower Atrai basin) to represent soils with very low $(<1 \%)$, low $(1-1.7 \%)$, medium (1.7-3.5\%), and high (>3.5\%) OM content [25]. For representing AEZ-7, Sonatola Upazila, Bogra, for AEZ-3, Pirganj Upazila, Rangpur, for AEZ-9, Bangladesh Agricultural University, Mymensingh, and for AEZ-5, Adamdighi Upazila, Bogra, Bangladesh locations were selected (Figure 1). The climate is characterized as the subtropical monsoon with moderately high temperature and heavy

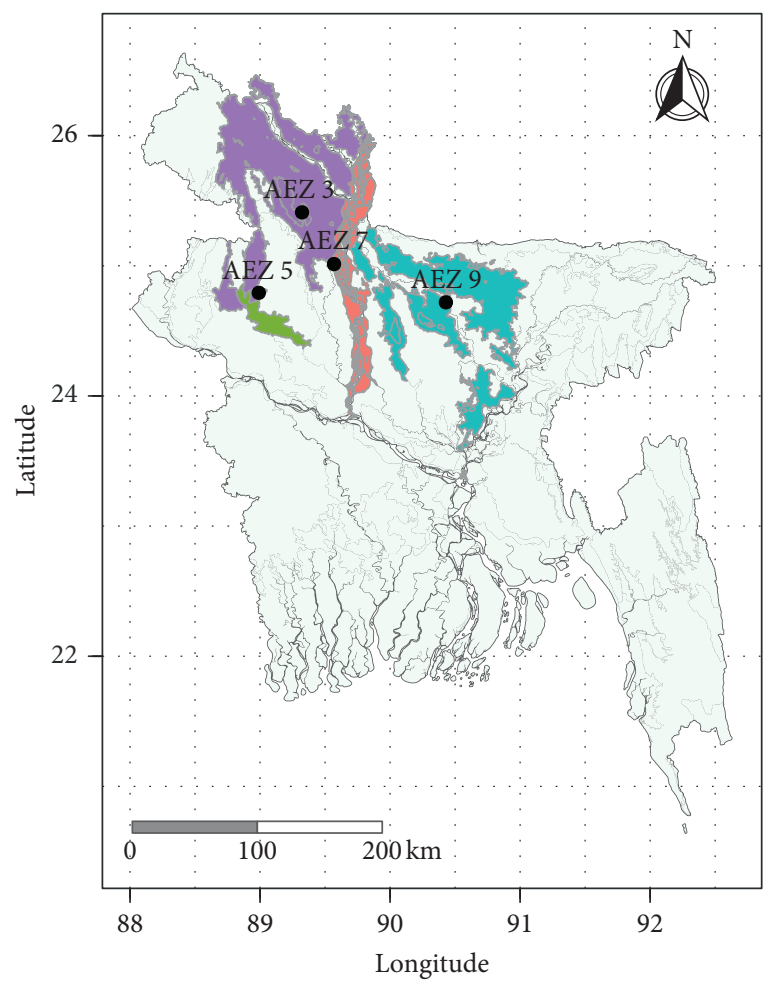

FIgURE 1: Geographical location of the selected sites of Bangladesh. Four coloured regions are showing the four selected agroecological zones (AEZs) of Bangladesh. The black dots are showing the position of the selected upazila (a subunit of a district in Bangladesh) in four AEZs: AEZ-7 (active Brahmaputra-Jamuna floodplain)= Sonatola Upazila, Bogra, AEZ-3 (Tista Meander floodplain)= Pirganj Upazila, Rangpur, AEZ-9 (Old Brahmaputra floodplain) = Bangladesh Agricultural University, Mymensingh, and AEZ-5 (lower Atrai basin) = Adamdighi Upazila, Bogra, Bangladesh .

rainfall during summer and low rainfall with moderately low temperature during the winter season.

A base survey was conducted in the selected upazilas to find out the most prevalent soil type, topography, and existing land use systems so that the selected samples can represent majority of the AEZ scenario. Based on the survey, four land use types, i.e., cropland, orchard, grass land, and fallow were nominated, and for each land use, 12 sites were selected per AEZ. Thus, 48 sites (12 per land use $\times 4$ land uses) per AEZ, i.e., total 192 sites for four AEZs were selected which were similar in climatic condition, topography, and soil type (Table 1). Medium high land was selected from all AEZs.

The cropped lands had been covered with rice, and mixed fruits (Litchi chinensis and Mangifera indica) trees were grown in orchard for about 15 years. Grassland had been covered with naturally grown deep-rooted native grass for $>10$ years, and the fallow land remained uncultivated for $>5$ years and covered with naturally regenerated grasses in all AEZs. Flood irrigation, conventional tillage, and typical fertilization were practiced in croplands where as the orchard was managed by only preparatory tillage, very rare irrigation, and yearly application of fertilizers + manure. The grassland and fallow lands remained undisturbed. 
Table 1: Climatic and soil data of the selected sites.

\begin{tabular}{|c|c|c|c|c|}
\hline $\begin{array}{l}\text { Soil organic matter content } \\
(\%)^{*}\end{array}$ & Agroecological zone & Soil description & $\begin{array}{c}\text { Average annual } \\
\text { precipitation }(\mathrm{mm})\end{array}$ & $\begin{array}{c}\text { Average annual } \\
\text { temperature } \\
\left({ }^{\circ} \mathrm{C}\right)\end{array}$ \\
\hline Very low $(<1)$ & $\begin{array}{l}\text { 7: active Brahmaputra-Jamuna } \\
\text { floodplain }\end{array}$ & Noncalcareous alluvium soil & 147 & 23.14 \\
\hline Low $(1-1.7)$ & 3: Tista Meander floodplain & $\begin{array}{c}\text { Noncalcareous dark grey } \\
\text { floodplain }\end{array}$ & 156 & 24.8 \\
\hline Medium (1.7-3.5) & 9: Old Brahmaputra floodplain & $\begin{array}{c}\text { Noncalcareous grey } \\
\text { floodplain }\end{array}$ & 212 & 25.9 \\
\hline High $(>3.5)$ & 5: lower Atrai basin & $\begin{array}{c}\text { Noncalcareous dark grey } \\
\text { floodplain }\end{array}$ & 128.3 & 25.6 \\
\hline
\end{tabular}

$*[25]$.

2.2. Soil Sampling. Surface soil depth $(0-15 \mathrm{~cm})$ was selected for sampling as it has an important role in agricultural production. Random soil samples of surface depth were collected from several spots of each site with auger and kept in polythene begs so that these remained in field moist condition. The random samples for each site were mixed thoroughly to make one composite sample. Soil core samples were also collected from three points of each site. After completion of collecting soil samples, the unwanted materials such as stones, granules, plant parts, and leaves were discarded from samples. The samples were dried at room temperature, crushed, sieved with a $2 \mathrm{~mm}$ mesh sieve, and preserved for subsequent laboratory analyses.

2.3. Physical Fractionation of Soils. Bulk soil samples from four land use types of each AEZs were fractionated into particulate OM (POM) and mineral associated particulate soil OM (MOM) by using the method adopted from Cambardella and Elliott [26]. About $20 \mathrm{~g}$ of $2 \mathrm{~mm}$ soil sample was transferred into a $100 \mathrm{~mL}$ sample bottle, and $60 \mathrm{~mL}$ of $5 \mathrm{gL}^{-1}$ sodium hexametaphosphate was added. Soil suspension was shaken in a horizontal shaker for overnight and then passed through a $53 \mu \mathrm{m}$ sieve. The soil samples retained on the sieve were considered as POM while, those that pass through the sieve were MOM fraction. Both the fractions were rinsed with water, dried in an oven at $40^{\circ} \mathrm{C}$, hand ground to fine powder, weighed, and stored in plastic vials for further analyses.

\subsection{Soil Sample Analysis}

2.4.1. Bulk Soil Properties. Bulk soils from four AEZs were analyzed for $\mathrm{pH}$, carbonate, electrical conductivity (EC), and texture. Soil $\mathrm{pH}$ and EC were measured by a glass electrode $\mathrm{pH}$ meter and conductivity meter, respectively, using a soilto-water ratio of $1: 5[27,28]$. Bulk density was determined by the core method. Carbonate and bicarbonate were analyzed through the titration method. Particle size analysis was conducted by the hydrometer method [29]. All laboratory analytical measurements of individual bulk soil sample were performed in triplicate.

2.4.2. Organic Carbon and Nitrogen Determination in Bulk Soils and Soil Fractions. Soil OC and total nitrogen (N) content of bulk soils and two soil fractions were measured for all four AEZs' samples. The OC content of the soil samples was determined by the wet oxidation method [30], and the total $\mathrm{N}$ content was determined following the microKjeldahl method [31].

2.5. Statistical Analysis. Analysis of variance was performed to find out the effects of land use on bulk soil and fractionated OC pools for both AEZs. Variation in soil OC and $\mathrm{N}$ due to native $\mathrm{OM}$ content was also determined. All the statistical analyses were performed using the software package IBM SPSS 21.0.

\section{Results and Discussion}

3.1. General Soil Characteristics. The soil type of all four land uses in AEZ-7 was noncalcareous alluvium, in AEZs-3 and 5, it was noncalcareous dark grey floodplain, and for AEZ-9, it was noncalcareous grey floodplain (Table 1). All the collected soils from four AEZs were nonsaline (EC: AEZ-7, 93-233; AEZ-3, 66-182; AEZ-9, 48-181; and AEZ-5, 70-213 $\left.\mu \mathrm{S} \mathrm{cm}{ }^{-1}\right) . \mathrm{pH}$ value ranged from 5.07 to 7.94 . All the soils were slightly acidic except AEZ-9, slightly alkaline in reaction ( $\mathrm{pH} \leq 7.26-7.94)$ (Table 2). The texture of the studied soils of different land uses was similar for all AEZs, i.e., silt loam, having $25-39 \%$ sand, $48-64 \%$ silt, and 9-15\% clay (Table 2).

\subsection{Effect of Land Use on Soil Organic Carbon and Nitrogen}

3.2.1. Total Organic Carbon. Total OC in bulk soils of land uses of four AEZs ranged between 0.39 and $1.79 \%$ (Figure 2(a)). The OC contents were in line with their native OM status. Soils of the AEZ 5 had the uppermost OC content (1.31-1.79\%), followed by the AEZ-9 (0.83-1.47\%) > AEZ-3 (0.44-0.71\%) and AEZ-7 (0.39-0.48\%). Total OC was significantly different among the land uses for specific AEZ and between AEZs (Figure 2(a), SI Tables 1 and 2). Fallow land soil had the highest OC in AEZs-7 (0.48\%) and 3 (0.71\%), and in AEZs-9 and 5, the highest soil OC was found in grassland (1.47 and 1.79\%, respectively). In AEZs-7 and 3, the highest percent of OC was followed by grassland >orchard $>$ cropland, and it was orchard $>$ fallow $>$ cropland in AEZs-9 and 5 (Figure 2(a)). This trend is matched with the 
TABLE 2: General properties of bulk soils.

\begin{tabular}{|c|c|c|c|c|c|c|}
\hline Agroecological zone & Land use & $\mathrm{pH}$ & $\begin{array}{c}\mathrm{EC} \\
(\mu \mathrm{s} / \mathrm{cm})\end{array}$ & Sand & $\begin{array}{l}\text { Silt } \\
(\%)\end{array}$ & Clay \\
\hline \multirow{4}{*}{7} & Cropland & 5.70 & 165 & 25 & 64 & 11 \\
\hline & Orchard & 5.84 & 167 & 37 & 54 & 9 \\
\hline & Grassland & 6.17 & 233 & 33 & 58 & 9 \\
\hline & Fallow & 6.24 & 93 & 29 & 64 & 7 \\
\hline \multirow{4}{*}{3} & Cropland & 5.20 & 66 & 30 & 57 & 13 \\
\hline & Orchard & 4.80 & 92 & 33 & 56 & 11 \\
\hline & Grassland & 5.07 & 94 & 37 & 50 & 13 \\
\hline & Fallow & 4.85 & 182 & 34 & 56 & 10 \\
\hline \multirow{4}{*}{9} & Cropland & 7.35 & 48 & 32 & 54 & 14 \\
\hline & Orchard & 7.94 & 181 & 39 & 52 & 9 \\
\hline & Grassland & 7.27 & 111 & 36 & 49 & 13 \\
\hline & Fallow & 7.33 & 142 & 39 & 52 & 9 \\
\hline \multirow{4}{*}{5} & Cropland & 5.80 & 213 & 31 & 54 & 15 \\
\hline & Orchard & 5.61 & 70 & 33 & 55 & 12 \\
\hline & Grassland & 5.75 & 78 & 34 & 53 & 13 \\
\hline & Fallow & 5.62 & 108 & 32 & 56 & 12 \\
\hline
\end{tabular}

All parameters representing mean values, except particle size analysis. Standard error (S.E.) for $\mathrm{pH}=0.005-0.12$ and $\mathrm{EC}=0-4$.

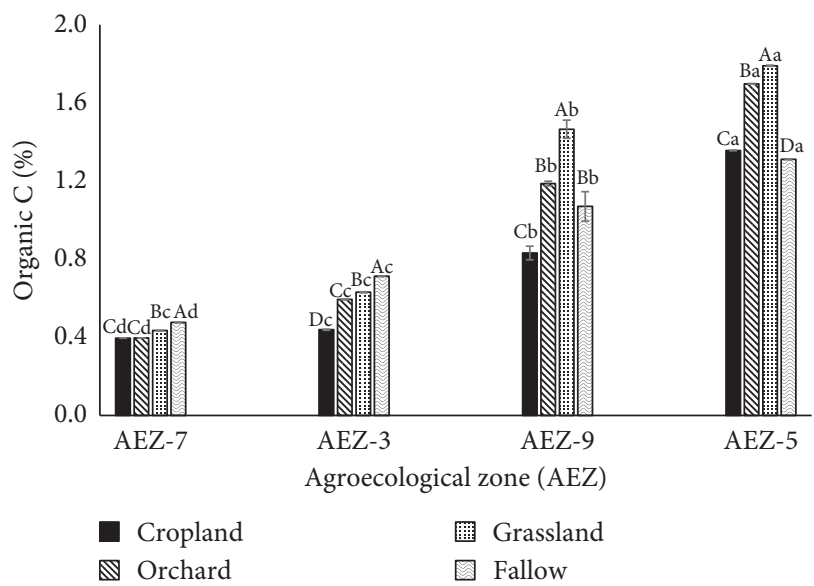

(a)

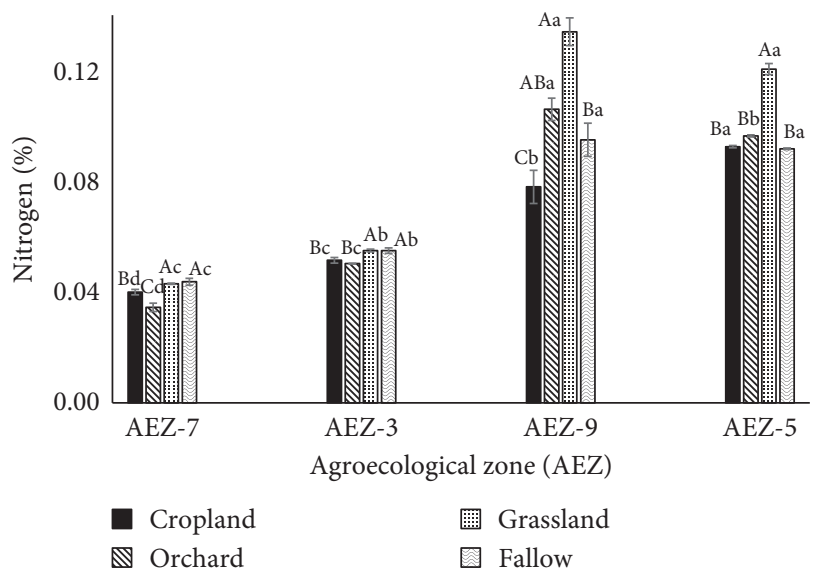

(b)

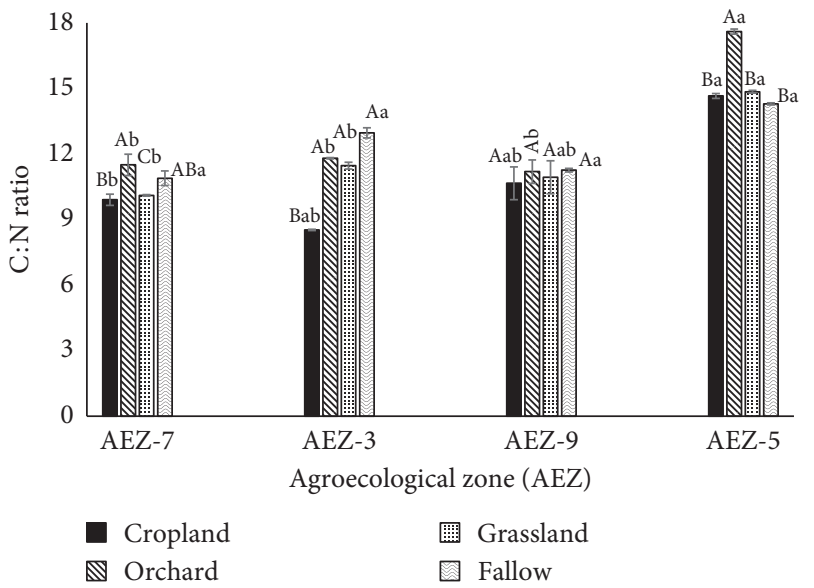

(c)

Figure 2: Amount of total organic carbon (a), nitrogen (b), and $\mathrm{C}: \mathrm{N}$ ratio (c) in bulk soils of four agroecological zones (AEZs) under different land uses. Vertical bars represent standard error. Uppercase letters indicate significant differences $(p<0.01)$ among land uses of the corresponding AEZ, and lowercase letters indicate significant differences between AEZs at corresponding land use. 
contribution of the land use systems in regards to the addition of OM to the surface soil. This result can be attributed to the above biomass and fine root density of naturally grown grasses and shrubs in grasslands $[32,33]$. This indicates that grassland (natural/fallow) is more beneficial to surface OC sequestration than orchard/tree plantation or cultivated cropland. This finding agrees with the results of many previous studies [34-36]. As for example, Lugo and Brown [37] found that tropical grasslands could accumulate more OC than the adjacent forests. Tate et al. [38] reported that the OC storage in the total profile was $13 \%$ higher in a grassland than in a forest and crop land. A review by Conant et al. [39] reported that conversion from native rain forests to grassland increased the OC in nearly $70 \%$ of the reviewed studies. Guo and Gifford [9] indicated that OC stocks could be higher under natural grassland than under natural forest.

The total organic $\mathrm{N}$ ranged between 0.03 and $0.13 \%$ in all the soils (Figure 2(b)). The variation and trend were almost similar to the OC among the land uses and AEZs. Overall, the highest $\mathrm{N}$ content was found in grassland soils of all four AEZs and the lowest was in orchard soils for AEZs-7 and 3 and cropland soils for AEZs-9 and 5.

The $\mathrm{C}: \mathrm{N}$ ratio ranged between 9.9 and 17.6 in all soils (Figure $2(\mathrm{c})$ ). The $\mathrm{C}: \mathrm{N}$ ratio varied among the land uses and also between AEZs, with few exceptions (SI Tables 1 and 2). These differences in $\mathrm{C}: \mathrm{N}$ ratios among land uses possibly reflect variations in composition of organic residues entering the soil OM pool and could be attributed to contrasting vegetation covers $[24,40]$. Overall, the narrowest ratio was observed in cropland soils and the highest was in either orchard or fallow land soils in all four AEZs. This indicates the higher mineralization and oxidation of OM in cultivated (disturbed) soils [41,42]. The $\mathrm{C}: \mathrm{N}$ ratio of orchard soils was relatively higher than their respective cropland which is expected since orchard soil got less disturbed per year than the three times rice cultivated soils of the cropland.

If we consider native grassland as nondisturbed soil, then about up to $43 \%$ OC was depleted after cultivation (cropland $>$ orchard), even OC depletion (27\%) was also observed in Fallow land, particularly in AEZs-9 and 5. In Bangladesh, fallow lands often use as open grazing field for cattle which could be a reason for OC depletion through above biomass reduction.

3.2.2. Soil Organic Carbon Pools. The physical fractionation separated: (i) sand and POM $(>53 \mu \mathrm{m})$ and (ii) silt + clay along with their associated $\mathrm{OM}(<53 \mu \mathrm{m})$, i.e., MOM $[20,26]$.

On a mass basis, POM fractions were more abundant than MOM in all land uses for AEZs-7 and 3 (Figures 3(a) and $3(\mathrm{~b})$ ), while the abundance pattern was opposite in case of AEZs-9 and 5 (Figures 3(c) and 3(d)). For POM fractions, fallow land soil had the highest amount followed by the orchard >cropland > grassland for AEZs-7 and 3 and grassland >cropland >orchard soils for AEZs-9 and 5 (Figure 3). Although this trend for MOM fraction was not very consistent among the land uses and AEZs, the overall trend was as cropland > grassland >orchard >fallow (Figure 3).
Effect of land use on POM fraction associated OC (POC) and mineral associated OC (MOC) was significant for four AEZs (Table 3 and SI Table 3). In all cases, the POC was highest in orchard soils $(0.72-1.91 \%)$ followed by fallow $(0.81-1.61 \%)>$ grassland $\quad(0.60-1.84 \%)>$ cropland $(0.40-1.41 \%)$. On the contrary, the MOC showed different trends highest in fallow land $(0.81-1.91 \%)$ followed by grassland $(0.72-1.81 \%)>$ cropland $(0.70-1.61 \%)>$ orchard (0.53-1.51\%) for all AEZs (Table 3). The MOC was significantly higher than POC in all cases except the orchard soils (SI Table 4). Although the trend of POC and MOC among the land uses, and variation between POC and MOC within the land use were similar for all four AEZs, overall the OC percent in both POC and MOC for an individual AEZ followed the trend of native OM content.

Nitrogen in POM and MOM fractions ranged between $0.02-0.11 \%$ and $0.03-0.13 \%$, respectively, in all soils (Table 3 ) and followed almost similar trend as OC among the land uses and AEZs (Table 3). The C: $\mathrm{N}$ ratios of the soils ranged from 11.3 to 20.7 (Table 3).

Here, the rapid decomposition of POM in cropland due to intensive cultivation operations could be the explanation for lowest POC, whereas accumulation of tree leaves and above biomass addition (from dried annual + perennial grasses) might be the reason for highest POC in orchard and fallow land, respectively. It is also noticeable that although the crop cultivation caused depletion of total OC in soils (Figure 2), the OC is mostly distributed to the MOM fractions (lowest POC + substantial percent of MOC). Similar findings were also reported by Cambardella and Elliott [26] and Álvaro-Fuentes et al. [43]. This might suggest that the lower OC in disturbed soil is the result of rapid POM decomposition. After microbial decomposition of the more labile components of POC pool, the remain parts become more stable form of OM [44]. The POM fractions are characterized by the wider C:N ratio [45] which is also true for these soils (C:N: 12.4-20.7), whereas the ratio is narrower (11.0-18.7) for MOM fractions (Table 3). It has been reported that the more stable OC has narrow C:N ratio since this OC is expected to be highly microbially processed $[45,46]$. Here, in spite of soil disturbance, rice-based crop field also showed considerable ability for sequestering OC $[47,48]$. The submerged conditions for growing paddy rice might decelerate soil OC mineralization up to a certain degree which could help to store OC in soils. Xin et al. [49] also reported higher storage of soil OC in paddy field than the adjacent dryland crop field.

3.3. Effect of Native Organic Matter Content on Soil Carbon Sequestration. Soil OM dynamics follow first order kinetics for the decomposition of various conceptual pools of $\mathrm{OM}$ $[13,50]$, which means that equilibrium C stocks are linearly proportional to C inputs [13]. This predicts that soil C stocks can be increased without limit, i.e., there are no assumptions of soil C saturation. The soil OC in this study were highly coincide with these existing literatures. Native OM content has a significant impact on total OC (Figure 2) and also has influence on MOC in soils of all land uses (Table 3). The total 


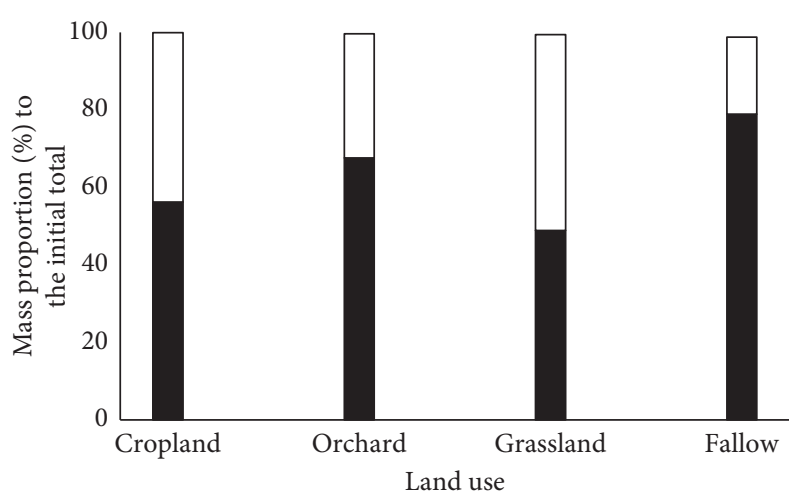

POM

$\square \mathrm{MOM}$

(a)

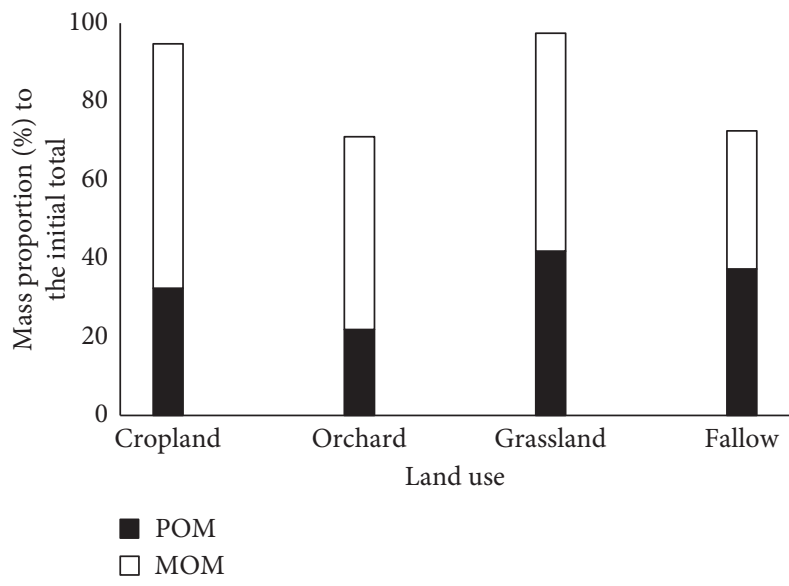

(c)

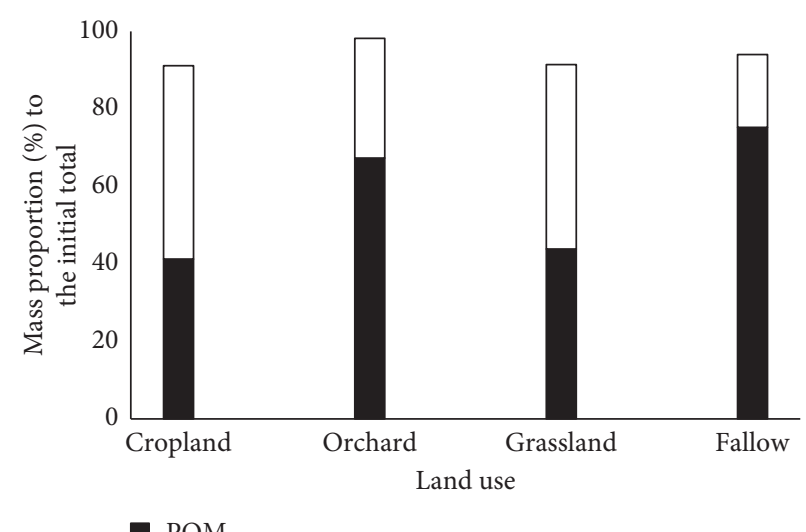

$\mathrm{POM}$

$\square \mathrm{MOM}$

(b)

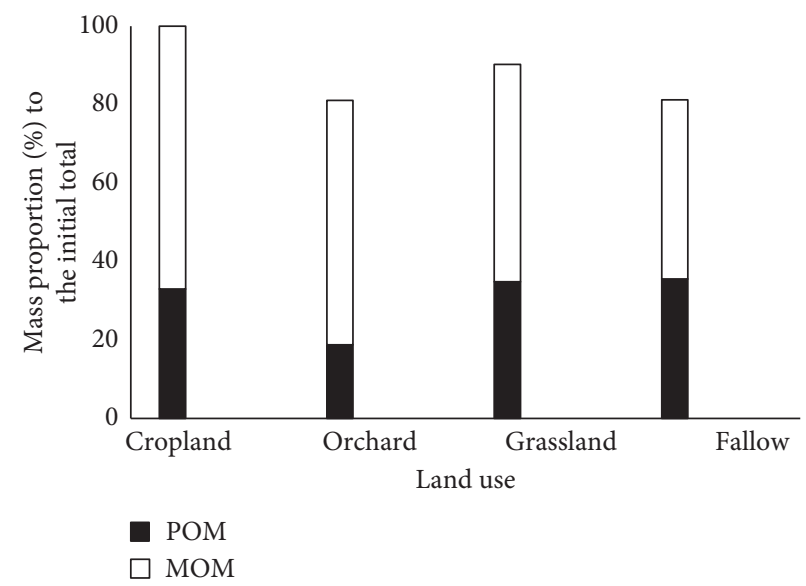

(d)

FIgURE 3: Mass proportion of the physical fractions (POM (particulate organic matter) $\geq 53 \mu \mathrm{m}$ and MOM (mineral associated organic matter $\leq 53 \mu \mathrm{m}$.) to the initial total soil of four agroecological zones (AEZs: $(\mathrm{a})=$ AEZ-7, $(\mathrm{b})=\mathrm{AEZ}-3$, (c) $=$ AEZ-9, and $(\mathrm{d})=$ AEZ-5) used in fractionation for different land uses.

TABle 3: Mean values of organic carbon (OC), nitrogen $(\mathrm{N})$ and $\mathrm{C}: \mathrm{N}$ ratio in physical fractions of soils from four agroecological zones under four land use types.

\begin{tabular}{|c|c|c|c|c|c|c|c|}
\hline \multirow{2}{*}{ Agroecological zone } & \multirow{2}{*}{ Land use } & \multicolumn{2}{|c|}{$\mathrm{OC}(\%)$} & \multicolumn{2}{|c|}{$\mathrm{N}(\%)$} & \multicolumn{2}{|c|}{$\mathrm{C}: \mathrm{N}$ ratio } \\
\hline & & POM & MOM & POM & MOM & POM & MOM \\
\hline \multirow{4}{*}{7} & Crop land & $0.42^{\mathrm{Cb}}$ & $0.78^{\mathrm{Ba}}$ & $0.02^{\mathrm{Cb}}$ & $0.04^{\mathrm{Ba}}$ & $18.3^{\mathrm{Ba}}$ & $17.9^{\mathrm{Bb}}$ \\
\hline & Orchard & $0.92^{\mathrm{Aa}}$ & $0.53^{\mathrm{Cb}}$ & $0.05^{\mathrm{Ab}}$ & $0.03^{\mathrm{Ca}}$ & $19.1^{\mathrm{Aa}}$ & $17.3^{\mathrm{Bb}}$ \\
\hline & Grassland & $0.75^{\mathrm{Bb}}$ & $0.81^{\mathrm{Ba}}$ & $0.04^{\mathrm{Bb}}$ & $0.06^{\mathrm{Aa}}$ & $19.6^{\mathrm{Aa}}$ & $13.2^{\mathrm{Cb}}$ \\
\hline & Fallow & $0.91^{\mathrm{Ab}}$ & $1.12^{\mathrm{Aa}}$ & $0.05^{\mathrm{Ab}}$ & $0.06^{\mathrm{Aa}}$ & $19.0^{\mathrm{Aa}}$ & $18.7^{\mathrm{Aa}}$ \\
\hline \multirow{4}{*}{3} & Crop land & $0.40^{\mathrm{Db}}$ & $0.70^{\mathrm{Ba}}$ & $0.02^{\mathrm{Bb}}$ & $0.05^{\mathrm{Aa}}$ & $17.5^{\mathrm{Da}}$ & $13.0^{\mathrm{Cb}}$ \\
\hline & Orchard & $0.71^{\mathrm{Ba}}$ & $0.61^{\mathrm{Cb}}$ & $0.04^{\mathrm{Ab}}$ & $0.05^{\mathrm{Aa}}$ & $19.5^{\mathrm{Ba}}$ & $11.3^{\mathrm{Db}}$ \\
\hline & Grassland & $0.60^{\mathrm{Cb}}$ & $0.72^{\mathrm{Ba}}$ & $0.03^{\mathrm{Bb}}$ & $0.04^{\mathrm{Ba}}$ & $20.7^{\mathrm{Aa}}$ & $16.1^{\mathrm{Ab}}$ \\
\hline & Fallow & $0.81^{\mathrm{Aa}}$ & $0.81^{\mathrm{Aa}}$ & $0.04^{\mathrm{Ab}}$ & $0.05^{\mathrm{Aa}}$ & $18.4^{\mathrm{Ca}}$ & $14.9^{\mathrm{Bb}}$ \\
\hline \multirow{4}{*}{9} & Crop land & $0.62^{\mathrm{Cb}}$ & $1.30^{\mathrm{Ca}}$ & $0.05^{\mathrm{Cb}}$ & $0.11^{\mathrm{Ba}}$ & $12.4^{\mathrm{Ca}}$ & $12.0^{\mathrm{Bb}}$ \\
\hline & Orchard & $1.85^{\mathrm{Aa}}$ & $0.90^{\mathrm{Db}}$ & $0.11^{\mathrm{Aa}}$ & $0.07^{\mathrm{Cb}}$ & $16.5^{\mathrm{Aa}}$ & $12.4^{\mathrm{Ab}}$ \\
\hline & Grassland & $1.44^{\mathrm{Bb}}$ & $1.58^{\mathrm{Ba}}$ & $0.09^{\mathrm{Bb}}$ & $0.14^{\mathrm{Aa}}$ & $16.2^{\mathrm{Aa}}$ & $11.0^{\mathrm{Cb}}$ \\
\hline & Fallow & $1.35^{\mathrm{Bb}}$ & $1.78^{\mathrm{Aa}}$ & $0.10^{\mathrm{Ab}}$ & $0.14^{\mathrm{Aa}}$ & $13.6^{\mathrm{Ba}}$ & $12.7^{\mathrm{Ab}}$ \\
\hline \multirow{4}{*}{5} & Crop land & $1.41^{\mathrm{Cb}}$ & $1.61^{\mathrm{Ba}}$ & $0.10^{\mathrm{Bb}}$ & $0.12^{\mathrm{Ba}}$ & $14.0^{\mathrm{Ca}}$ & $13.9^{\mathrm{Ba}}$ \\
\hline & Orchard & $1.91^{\mathrm{Aa}}$ & $1.51^{\mathrm{Bb}}$ & $0.11^{\mathrm{Ab}}$ & $0.12^{\mathrm{Ba}}$ & $17.9^{\mathrm{Aa}}$ & $13.0^{\mathrm{Cb}}$ \\
\hline & Grassland & $1.84^{\mathrm{Ab}}$ & $1.81^{\mathrm{Aa}}$ & $0.11^{\mathrm{Ab}}$ & $0.13^{\mathrm{Aa}}$ & $17.2^{\mathrm{Aa}}$ & $13.5^{\mathrm{Bb}}$ \\
\hline & Fallow & $1.61^{\mathrm{Bb}}$ & $1.91^{\mathrm{Aa}}$ & $0.10^{\mathrm{Bb}}$ & $0.12^{\mathrm{Ba}}$ & $16.3^{\mathrm{Ba}}$ & $15.9^{\mathrm{Aa}}$ \\
\hline
\end{tabular}

Here, POM (particulate organic matter) $\geq 53 \mu \mathrm{m}$ and MOM (mineral associated organic matter) $\leq 53 \mu \mathrm{m}$. Standard error (S.E.) for OC $=0.00-0.09, N=0-0.01$ and $\mathrm{C}: \mathrm{N}$ ratio $=0.01-0.65$. Uppercase letters indicate significant differences $(p<0.001)$ among land uses at corresponding fraction size for each AEZ and lowercase letters indicate significant differences $(p<0.001)$ between fractions at corresponding land use for each AEZ. 
OC as well as the MOC contents in the soils of four AEZs followed the trend as high $\mathrm{OM}>$ medium $\mathrm{OM}>$ low $\mathrm{OM}>$ very low OM. This might also suggest that the soils with relatively higher $\mathrm{OM}$ content did not reach to the $\mathrm{C}$ saturation limit and still have great potential for $\mathrm{OC}$ sequestration $[15,17]$.

\section{Conclusion}

The overall results indicate that soil OC was influenced by the impact of the land use and native soil OM content. Separated OC pools are the best indicator of OC status in regards to show the potential of soil for $\mathrm{C}$ storage rather than bulk soil total OC. Cultivation causes OC depletion which does not necessarily mean the depletion of stable OC. Less disturbed native (grassland) soils do not always aid in enhancing OC storage. It could rather depend on the type of vegetation cover, management practices, and soil type. Further research is needed to explore the specific explanation for this. Although the results showed higher proportion of stable $\mathrm{OC}$ in soils with higher native $\mathrm{OM}$ content than the soils with lower OM content, the OC storage potential can be increased even in the latter soils with proper management, e.g., regular residue addition, minimum tillage, and balanced fertilization, even if it is intensively cultivated land.

\section{Data Availability}

All data generated or analyzed during this study are included within the article.

\section{Disclosure}

The funders had no role in the design of the study; in the collection, analyses, or interpretation of data; in the writing of the manuscript; or in the decision to publish the results.

\section{Conflicts of Interest}

The authors declare that they have no conflicts of interest.

\section{Authors' Contributions}

Conceptualization, supervision, project administration, and funding acquisition were done by Sabina Yeasmin. Sabina Yeasmin, Eshara Jahan, Md. Ashik Molla, AKM Mominul Islam, and Md. Harun Or Rashid were responsible for formal analysis. Investigation was conducted by Sabina Yeasmin, Eshara Jahan, and Md. Ashik Molla. Resources were collected by, Sabina Yeasmin, AKM Mominul Islam, and Md. Parvez Anwar. Sabina Yeasmin, Eshara Jahan, and Md. Ashik Molla carried out writing and original draft preparation. Writing, reviewing, and editing were executed by AKM Mominul Islam, Md. Parvez Anwar, and $\mathrm{Md}$. Harun Or Rashid. Sabina Yeasmin and Md. Harun Or Rashid did visualization.

\section{Acknowledgments}

The corresponding author gratefully acknowledge the financial supports provided by The Word Academy of Sciences (TWAS) (research grant no. 17-387RG/CHE/ AS_I-FR3240297752) for purchasing equipment and the Ministry of Science and Technology, Government of the People's Republic of Bangladesh (project no. 39,00,0000.009.14.004.19/BS-75/86) for conducting research. Special thanks are extended to the physical support provided by the Department of Agricultural Extension (DAE) of the four selected upazilas in Bangladesh. Mr. Azahar of Agro Innovation Laboratory, Department of Agronomy and Mr. Habib of Humbolt Soil Testing Laboratory, Department of Soil Science, Bangladesh Agricultural University are also highly acknowledged for the help during collection, processing, and analyzing the soil samples, respectively.

\section{Supplementary Materials}

SI Table 1. $p$ values from the ANOVA showing the effect of land use on organic carbon (OC), nitrogen $(\mathrm{N})$, and $\mathrm{C}: \mathrm{N}$ ratios of bulk soils from four agroecological zones (AEZs). SI Table 2. $p$ values from the ANOVA showing the effect of agroecological zones on organic carbon (OC), nitrogen $(\mathrm{N})$, and $\mathrm{C}: \mathrm{N}$ ratios of bulk soils from four land uses. SI Table 3. $p$ values from the ANOVA showing the effect of land use on organic carbon (OC), nitrogen $(\mathrm{N})$, and $\mathrm{C}: \mathrm{N}$ ratios of soil fractions $(\mathrm{POM} \geq 53 \mu \mathrm{m}$ and $\mathrm{MOM} \leq 53 \mu \mathrm{m})$ from four agroecological zones (AEZs). SI Table 4. $p$ values from the ANOVA showing the variation of soil fractions on organic carbon (OC), nitrogen $(\mathrm{N})$, and $\mathrm{C}: \mathrm{N}$ ratios of soils from four land uses and agroecological zones (AEZs). (Supplementary Materials)

\section{References}

[1] R. Kiem and I. Kögel-Knabner, "Refractory organic carbon in particle-size fractions of arable soils II: organic carbon in relation to mineral surface area and iron oxides in fractions $<6 \mu \mathrm{m}$," Organic Geochemistry, vol. 33, no. 12, pp. 1699-1713, 2002.

[2] W. M. Post and K. C. Kwon, "Soil carbon sequestration and land-use change: processes and potential," Global Change Biology, vol. 6, no. 3, pp. 317-327, 2000.

[3] C. D. Evans, C. Freeman, L. G. Cork et al., "Evidence against recent climate induced destabilisation of soil carbon from 14C analysis of riverine dissolved organic matter," Geophysical Research Letters, vol. 34, no. 7, pp. 1-5, 2007.

[4] G. W. T. Wilson, C. W. Rice, M. C. Rillig, A. Springer, and D. C. Hartnett, "Soil aggregation and carbon sequestration are tightly correlated with the abundance of arbuscular mycorrhizal fungi: results from long-term field experiments," Ecology Letters, vol. 12, no. 5, pp. 452-461, 2009.

[5] S. Yeasmin, B. Singh, C. T. Johnston, and D. L. Sparks, "Organic carbon characteristics in density fractions of soils with contrasting mineralogies," Geochimica et Cosmochimica Acta, vol. 218, pp. 215-236, 2017.

[6] Z. Luo, E. Wang, and O. J. Sun, "Soil carbon change and its responses to agricultural practices in Australian agro- 
ecosystems: a review and synthesis," Geoderma, vol. 155, no. 3-4, pp. 211-223, 2010.

[7] A. Bhatia, P. K. Aggarwal, N. Jain, and H. Pathak, "Greenhouse gas emission from rice-wheat growing areas in India: spatial analysis and up scaling," Greenhouse Gases: Science and Technology, vol. 2, no. 2, pp. 115-125, 2011.

[8] T. B. Bruun, B. Elberling, A. Neergaard, and J. Magid, "Organic carbon dynamics in different soil types after conversion of forest to agriculture," Land Degradation \& Development, vol. 26, no. 3, pp. 272-283, 2015.

[9] L. B. Guo and R. M. Gifford, "Soil carbon stocks and land use change: a meta analysis," Global Change Biology, vol. 8, no. 4, pp. 345-360, 2002.

[10] E. Roose and B. Barthès, "Organic matter management for soil conservation and productivity restoration in Africa: a contribution from francophone research," Nutrient Cycling in Agroecosystems, vol. 61, pp. 159-170, 2001.

[11] I. Ismail, R. L. Blevins, and W. W. Frye, "Long-term No-tillage effects on soil properties and continuous corn yields," Soil Science Society of America Journal, vol. 58, no. 1, pp. 193-198, 1994.

[12] W. E. Larson, C. E. Clapp, W. H. Pierre, and Y. B. Morachan, "Effects of increasing amounts of organic residues on continuous corn: II. Organic carbon, nitrogen, phosphorus, and Sulfur1," Agronomy Journal, vol. 64, no. 2, pp. 204-209, 1972.

[13] K. Paustian, H. P. Collins, and E. A. Paul, "Management controls on soil carbon," in Soil Organic Matter in Temperate Agroecosystems, E. A. Paul, K. Paustian, E. T. Elliott, and C. V. Cole, Eds., pp. 15-49, CRC Press, Boca Raton, FL, USA, 1997.

[14] C. A. Campbell, R. P. Zentner, K. E. Bowren, L. TownleySmith, and M. Schnitzer, "Effect of crop rotations and fertilization on soil organic matter and some biochemical properties of a thick Black Chernozem," Canadian Journal of Soil Science, vol. 71, no. 3, pp. 377-387, 1991.

[15] J. Hassink, "The capacity of soils to preserve organic C and N by their association with clay and silt particles," Plant and Soil, vol. 191, no. 1, pp. 77-87, 1997.

[16] J. Six, R. T. Conant, E. A. Paul, and K. Paustian, "Stabilization mechanisms of soil organic matter: implications for C-saturation of soils," Plant and Soil, vol. 241, no. 2, pp. 155-176, 2002.

[17] C. E. Stewart, K. Paustian, R. T. Conant, A. F. Plante, and J. Six, "Soil carbon saturation: concept, evidence and evaluation," Biogeochemistry, vol. 86, no. 1, pp. 19-31, 2007.

[18] K. Eusterhues, C. Rumpel, M. Kleber, and I. Kögel-Knabner, "Stabilisation of soil organic matter by interactions with minerals as revealed by mineral dissolution and oxidative degradation," Organic Geochemistry, vol. 34, no. 12, pp. 1591-1600, 2003.

[19] J. Leifeld and I. Kögel-Knabner, "Soil organic matter fractions as early indicators for carbon stock changes under different land-use?" Geoderma, vol. 124, no. 1-2, pp. 143-155, 2005.

[20] S. Jagadamma and R. Lal, "Integrating physical and chemical methods for isolating stable soil organic carbon," Geoderma, vol. 158, no. 3-4, pp. 322-330, 2010.

[21] E. Jones and B. Singh, "Organo-mineral interactions in contrasting soils under natural vegetation," Frontiers in Environmental Science, vol. 2, no. 2, pp. 1-15, 2014.

[22] I. Celik, "Land-use effects on organic matter and physical properties of soil in a southern Mediterranean highland of Turkey," Soil and Tillage Research, vol. 83, no. 2, pp. 270-277, 2005.
[23] X. Fang, Z. Xue, B. Li, and S. An, "Soil organic carbon distribution in relation to land use and its storage in a small watershed of the Loess Plateau, China," Catena, vol. 88, no. 1, pp. 6-13, 2012.

[24] N. Islam, S. Hossen, and A. Baten, "Soil carbon and nitrogen dynamics in agricultural soils of Mymensingh, Bangladesh," International Journal of Agricultural and Biosystems Engineering, vol. 1, pp. 1-8, 2016.

[25] BARC (Bangladesh Agricultural Research Council), Land Degradation Situation of Bangladesh, Soil Science Division, Bangladesh Agricultural Research Council, Farmgate, Dhaka, Bangladesh, 1999.

[26] C. A. Cambardella and E. T. Elliott, "Particulate soil organicmatter changes across a grassland cultivation sequence," Soil Science Society of America Journal, vol. 56, no. 3, pp. 777-783, 1992.

[27] M. L. Jackson, Soil Chemical Analysis, p. 498, Prentice Hall, Inc, Englewood Chiffs, NY, USA, 1962.

[28] A. L. Page, R. H. Miller, and D. R. Keeney, Methods Of Soil Analysis (Part 2), American Society of Agronomy and Soil Science Society of America, Madison, WI, USA, 1982.

[29] G. J. Bouyoucos, "Hydrometer method improved for making particle size analyses of Soils1," Agronomy Journal, vol. 54, no. 5, pp. 464-465, 1962.

[30] A. Walkley and I. A. Black, "An examination of the degtjareff method for determining soil organic matter, and a proposed modification of the chromic acid titration method," Soil Science, vol. 37, no. 1, pp. 29-38, 1934.

[31] J. M. Bremner, "Determination of nitrogen in soil by the Kjeldahl method," The Journal of Agricultural Science, vol. 55, no. 1, pp. 11-33, 1960.

[32] X. Cheng, M. Huang, and M. Shao, "Vertical distribution of representative plantation's fine root in wind-water erosion crisscross region, Shenmu," Acta Botany Boreal Occident Sinica, vol. 27, pp. 321-327, 2007, in Chinese.

[33] X. Fu, M. Shao, X. Wei, and R. Horton, "Soil organic carbon and total nitrogen as affected by vegetation types in Northern Loess Plateau of China," Geoderma, vol. 155, no. 1-2, pp. 31-35, 2010.

[34] Z. Jin, Y. Dong, Y. Wang et al., "Natural vegetation restoration is more beneficial to soil surface organic and inorganic carbon sequestration than tree plantation on the Loess Plateau of China," Science of The Total Environment, vol. 485-486, pp. 615-623, 2014.

[35] A. Don, J. Schumacher, and A. Freibauer, "Impact of tropical land-use change on soil organic carbon stocks - a metaanalysis," Global Change Biology, vol. 17, no. 4, pp. 1658-1670, 2011.

[36] L. Chen, J. Gong, B. Fu, Z. Huang, Y. Huang, and L. Gui, "Effect of land use conversion on soil organic carbon sequestration in the loess hilly area, loess plateau of China," Ecological Research, vol. 22, no. 4, pp. 641-648, 2007.

[37] A. E. Lugo and S. Brown, "Management of tropical soils as sinks or sources of atmospheric carbon," Plant and Soil, vol. 149, no. 1, pp. 27-41, 1993.

[38] K. R. Tate, N. A. Scott, D. J. Ross, A. Parshotam, and J. J. Claydon, "Plant effects on soil carbon storage and turnover in a montane beech (Nothofagus) forest and adjacent tussock grassland in New Zealand," Soil Research, vol. 38, no. 3, pp. 685-698, 2000.

[39] R. T. Conant, K. Paustian, and E. T. Elliott, "Grassland management and conversion into grassland: effects on soil carbon," Ecological Applications, vol. 11, pp. 343-355, 2001. 
[40] F. Yimer, S. Ledin, and A. Abdelkadir, "Changes in soil organic carbon and total nitrogen contents in three adjacent land use types in the Bale Mountains, south-eastern highlands of Ethiopia," Forest Ecology and Management, vol. 242, no. 23, pp. 337-342, 2007.

[41] A. Golchin and H. Asgari, "Land use effects on soil quality indicators in north-eastern Iran," Soil Research, vol. 46, no. 1, pp. 27-36, 2008.

[42] J. M. Oades, "Soil organic matter and structural stability: mechanisms and implications for management," Biological Processes and Soil Fertility, vol. 76, pp. 319-337, 1984.

[43] J. Álvaro-Fuentes, M. V. López, C. Cantero-Martinez, and J. L. Arrúe, "Tillage effects on soil organic carbon fractions in mediterranean dryland agroecosystems," Soil Science Society of America Journal, vol. 72, no. 2, pp. 541-547, 2008.

[44] E. A. Paul, "Dynamics of organic matter in soils," Biological Processes and Soil Fertility, vol. 76, pp. 275-285, 1984.

[45] W. T. Baisden, R. Amundson, A. C. Cook, and D. L. Brenner, "Turnover and storage of $\mathrm{C}$ and $\mathrm{N}$ in five density fractions from California annual grassland surface soils," Global Biogeochemical Cycle, vol. 16, pp. 11-17, 2002.

[46] A. L. Wright, F. Dou, and F. M. Hons, "Crop species and tillage effects on carbon sequestration in subsurface soil," Soil Science, vol. 172, no. 2, pp. 124-131, 2007.

[47] B. Majumder, B. Mandal, and P. K. Bandyopadhyay, "Soil organic carbon pools and productivity in relation to nutrient management in a 20 -year-old rice-berseem agroecosystem," Biology and Fertility of Soils, vol. 44, no. 3, pp. 451-461, 2008.

[48] G. X. Pan, L. Q. Li, L. S. Wu, and X. H. Zhang, "Storage and sequestration potential of topsoil organic carbon in China's paddy soils," Global Change Biology, vol. 10, no. 3, pp. 79-92, 2003.

[49] Z. Xie, J. Zhu, G. Liu et al., "Soil organic carbon stocks in China and changes from 1980s to 2000s," Global Change Biology, vol. 13, no. 9, pp. 1989-2007, 2007.

[50] W. B. McGill, "Review and classification of ten soil organic matter models," in Evaluation Of Soil Organic Matter Models, D. S. Powlson, P. Smith, and J. U. Smith, Eds., NATO ANSI Series, Springer-Verlag, Berlin, Germany, pp. 111-132, 1996. 